\title{
Decreased Serum Levels of S-100B Protein Reflect Successful Treatment Effects in a Rabbit Model of Acute Ischemic Stroke
}

\author{
Sean D. Woods ${ }^{1}$, Rene Flores ${ }^{1}$, Paula K. Roberson ${ }^{2}$, John D. Lowery ${ }^{3}$, Robert D. Skinner ${ }^{4}$ and \\ William C. Culp*,
}

\author{
Departments of ${ }^{1}$ Radiology, ${ }^{2}$ Biostatistics, ${ }^{3}$ Laboratory Animal Medicine, ${ }^{4}$ Neurobiology and Developmental Sciences, at \\ the University of Arkansas for Medical Sciences, Little Rock, AR 72205, USA
}

\begin{abstract}
Serum levels of S-100B were investigated as a marker for infarct volume and response to treatment following acute ischemic stroke in rabbits. Following subselective angiography, rabbits $(n=31)$ were embolized by injection of a 3day-old blood clot $(0.6 \times 4.0-\mathrm{mm})$ into the internal carotid artery. Treatment began 1-hr post-embolization, groups included: Control ( $\mathrm{n}=8$, embolization only), tissue plasminogen activator (tPA, $\mathrm{n}=12,0.9 \mathrm{mg} / \mathrm{kg}$ ), and perflutren lipid microbubbles with transcranial ultrasound (MB+US, $\mathrm{n}=11, \mathrm{MB}$ at $0.16 \mathrm{mg} / \mathrm{kg}$, US at $1-\mathrm{MHz}$ pulsed-wave, $0.8 \mathrm{~W} / \mathrm{cm}^{2}$ for $1-\mathrm{hr}$ ). Serum S-100B levels were significantly increased $(\mathrm{P}<0.01)$ 24-hours following embolization in control $(3.1$-fold over baseline) and tPA (2.9-fold) groups, while treatment with MB+US resulted in an attenuated, non-significant $(\mathrm{P}=0.221)$ increase (1.6-fold). Twenty-four hour infarct volumes averaged $4.76 \% \pm 1.16 \%$ for controls, $2.25 \% \pm 0.95 \%$ for rabbits treated with tPA ( $\mathrm{P}=0.32$ vs. control), and $0.79 \% \pm 0.99 \%$ for rabbits treated with $\mathrm{MB}+\mathrm{US}(\mathrm{P}=0.04$ vs. control). Twenty-four hour concentrations of $\mathrm{S}-100 \mathrm{~B}$ were positively correlated with infarct volume $(\mathrm{r}=0.59, \mathrm{P}=0.0004)$.
\end{abstract}

Keywords: Stroke, animal model, biomarkers, S-100B.

\section{INTRODUCTION}

The astroglial protein S-100B has been suggested as a potential biomarker for the diagnosis of ischemic stroke. This calcium binding protein is found abundantly in the cytosol of astrocytes and Schwann cells, and characteristics such as solubility and organ specificity make it desirable for investigation [1]. Previous studies have demonstrated that S100B is elevated in peripheral blood in the hours and days following acute cerebral ischemia. Instances of tissue hypoxia most likely release S-100B from damaged astrocytes, and the protein can enter the peripheral circulation through the damaged blood-brain barrier and blood-cerebrospinal fluid barrier [2]. Serial measurements of serum S-100B levels have been shown to correlate to several primary and secondary end points in human strokes, including infarct volume, brain edema, and long-term functional outcomes [1, 37]. Elevated blood concentrations of S-100B have been reported in some animal models following acute cerebral ischemia, but studies are limited that evaluate S-100B as a marker of cerebral tissue damage and treatment effects [810]. We chose a rabbit embolic stroke model because the successful introduction of tissue plasminogen activator (tPA) in stroke therapy began in a rabbit model [11].

\section{MATERIALS AND METHODOLOGY}

Animal procedures were approved by the Institutional Animal Care and Use Committee. New Zealand White rabbits $(n=31$; mean body weight $=5.2 \pm 0.04 \mathrm{~kg})$ were used in this study.

*Address correspondence to this author at the Department of Radiology, University of Arkansas for Medical Sciences, 4301 W. Markham St., Slot 556, Little Rock, AR 72205-7199, USA; Tel: (501) 686-6910; Fax: (501) 686-6900; E-mail: culpwilliamc@uams.edu
Surgical and angiographic procedures were described previously [12]. Using standard angiographic techniques and a femoral artery approach, a modified $65-\mathrm{cm}$ angled-tip $3 \mathrm{~F}$ catheter (SlipCath; Cook Inc.; Bloomington, IN) was advanced to the common carotid artery and subsequently into the internal carotid artery (ICA) using a single plane C-arm digital subtraction angiography machine (OEC 9800; GE Healthcare; Salt Lake City, UT). Angiography documented the cerebral vasculature and follow-up angiography confirmed the immediate occlusion of branches of the ICA following the injection of an autologous blood clot embolus. The cylindrical clot (4.0-mm length $\mathrm{x} 0.6-\mathrm{mm}$ diameter) was produced in glass tubing at $37^{\circ} \mathrm{C}$ for 6 hours followed by incubation at $4^{\circ} \mathrm{C}$ for 72 hours. Flow usually carried the clot to the middle cerebral artery.

Treatment was initiated 1 hour post embolization. Rabbits were randomly assigned to one of three groups: Control $(\mathrm{n}=8$, embolization only), tissue plasminogen activator (tPA) $(\mathrm{n}=12)$, and Perflutren Lipid Microbubbles+Ultrasound $(\mathrm{MB}+\mathrm{US})(\mathrm{n}=11)$, a novel thrombolytic technique. MB (Definity; Lantheus Medical Imaging; North Billerica, MA) were administered IV $(0.16 \mathrm{mg} / \mathrm{kg})$ over $30 \mathrm{~min}$. Ultrasound (Sonicator 716; Mettler Electronics; Anaheim, CA) was applied transcranially for 1 hour at $1-\mathrm{MHz}$ pulsed-wave, 0.8 $\mathrm{W} / \mathrm{cm}^{2}$, and tPA (Cathflo Activase; Genentech; South San Francisco, CA) was administered IV $(0.9 \mathrm{mg} / \mathrm{kg})$ over a 1 hour period.

Blood samples (2-3 $\mathrm{ml})$ were collected from an auricular vein before embolization (baseline) and at 3 and 24 hours following embolization. The serum was separated by centrifugation and stored at $-80^{\circ} \mathrm{C}$ until analysis. Following the instructions of the Nexus Dx S-100 Enzyme-linked immunosorbent assay test kit (International Point of Care, Inc.; 
Toronto, Ontario, Canada) the S-100B serum concentrations were measured. The test applies the sandwich ELISA technique utilizing murine monoclonal anti-S-100 protein coated microplate wells, diluted serum, standards and controls. The optical density of the oxidized enzymatic product was proportional to the concentration of S-100B in the sample, and a set of S-100B protein standards was used to construct a standard curve of absorbance. From this the S-100B concentrations in test serum samples were calculated.

Twenty-four hours following embolization, rabbits were sacrificed by intravenous administration of $1.5-\mathrm{mL}$ of pentobarbital (Euthasol; Virbac Corp.; Fort Worth, TX). The 24hour time point was chosen as part of a larger stroke study to permit both complete development of tissue infarction and three serial measurements of S-100B levels that demonstrate a time-dependent increase in serum levels. The brain was harvested, immediately placed in chilled physiological saline for 1 hour, and then sliced coronally at 4-mm intervals using a chilled brain mold (RBM-7000C; ASI Instruments Inc.; Warren, MI). Coronal brain sections ( $\mathrm{n}=8$ in each rabbit) were placed in 1\% 2,3,5-triphenyltetrazolium chloride (TTC) (Sigma-Aldrich; St. Louis, MO) for 45 minutes at $37^{\circ} \mathrm{C}$, fixed in $10 \%$ formalin, and digitally photographed. Areas of infarction were measured using digital analysis (NIH ImageJ). Percent infarct volume was calculated by dividing the sum of the infarct volumes into the sum of the section volumes and multiplying by $100 \%$.

Percent infarct volume was compared among treatment groups using one-way ANOVA. The Bonferroni testing adjustment was used for comparison of each treatment group with the control. Percent infarct volume for each group is reported as the least square mean \pm standard error as generated by PROC GLM in the SAS ${ }^{\circledR}$ software (SAS Inst. Inc.; Cary, NC). Three hour and 24-hour S-100B values for each rabbit were divided by that rabbit's baseline measurement to create 3- and 24-hour fold change values. The effects of treatment and time on these S-100B fold changes were tested using an unstructured covariance matrix in PROC MIXED in $\mathrm{SAS}^{\circledR}$, a repeated-measures ANOVA procedure, followed by individual group comparisons using least squares means. Fold changes are reported as least squares means \pm standard errors. Pearson correlation was used to evaluate the association between percent infarct volume and 24-hour S-100B values.

\section{RESULTS}

Thirty-one rabbits completed the protocol and were evaluated for serum S-100B levels and infarct volumes. The $\mathrm{S}-100 \mathrm{~B}$ fold increase over baseline was influenced by time $(\mathrm{P}=0.0002)$ and treatment $(\mathrm{P}=0.04)$. Control rabbits had a 3.1-fold increase in S-100B at 24 hours (Fig. 1), and this increase differed from baseline values $(\mathrm{P}=0.001)$. Similarly, rabbits treated with $\mathrm{tPA}$ had a 2.9 -fold increase in S-100B at 24 hours which differed from baseline $(\mathrm{P}=0.0002)$. Treatment with $\mathrm{MB}+\mathrm{US}$, however, resulted in only a 1.6-fold increase in S-100B at 24 hours which did not differ from baseline $(P=0.221)$. Each treatment group had numerically increased S-100B levels at 3 hours, but only the tPA group had a significant $(\mathrm{P}<0.05)$ increase. Infarct volume averaged $4.76 \% \pm 1.16 \%$ for control rabbits (Fig. 2), $2.25 \% \pm 0.95 \%$ for rabbits treated with $\mathrm{tPA}$ (Bonferroni correction $\mathrm{P}=0.32$ com- pared to control), and $0.79 \% \pm 0.99 \%$ for rabbits treated with $\mathrm{MB}+\mathrm{US}$ (Bonferroni correction $\mathrm{P}=0.04$ compared to control). Concentrations of S-100B at 24 hours were positively correlated with percent infarct volume ( $\mathrm{r}=0.59, \mathrm{P}=0.0004)$.

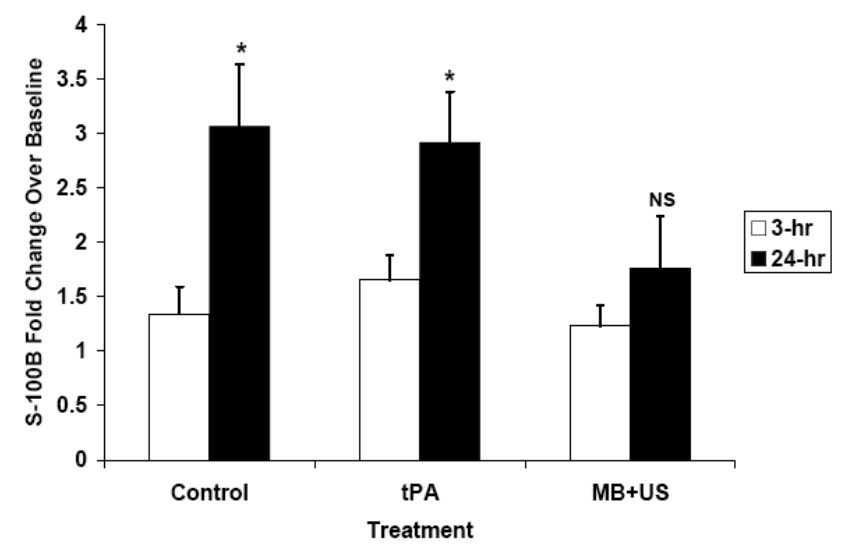

Fig. (1). Using initial pre-stroke values as the baseline, S-100B normalized fold values increased significantly with time following stroke in controls and tPA groups. Treatment with MB+US resulted in a smaller increase that did not reach significance, reflecting less damage to the brain. ( $* \mathrm{P}<0.001$ compared to baseline, NS=nonsignificant).

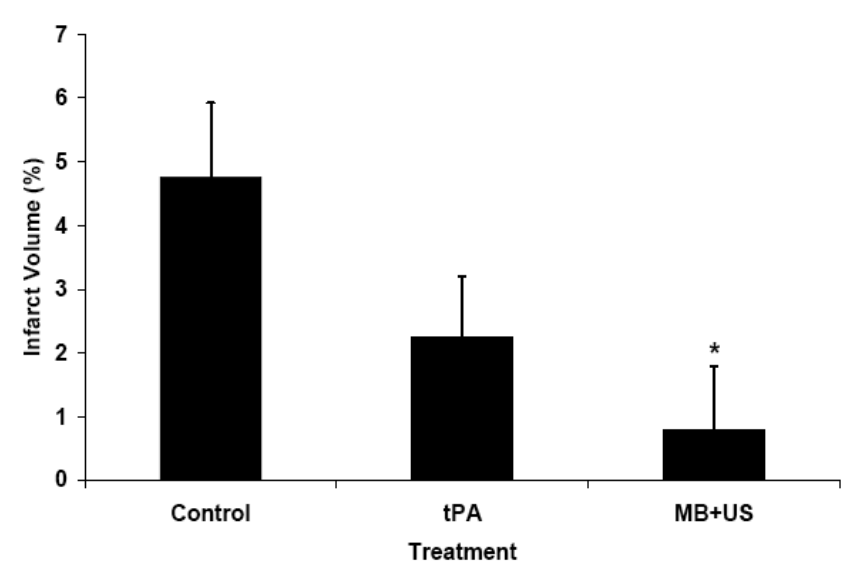

Fig. (2). Percent infarct volumes of rabbits at twenty-four hours following embolization show numerically decreased values for treatment with tPA $(\mathrm{P}=0.32$ compared to control, Bonferroni corrected) and significantly decreased values for treatment with $\mathrm{MB}+\mathrm{US}$ ( $\mathrm{P}=0.04$ compared to control, Bonferroni corrected).

\section{DISCUSSION}

The present study demonstrated significant elevations in serum S-100B at 24 hours following embolic stroke in control rabbits. Microbubble therapy with transcranial ultrasound significantly attenuated elevations in serum S-100B levels, which correlated significantly with reductions in infarct volumes. Significantly smaller stroke volumes and suppressed S-100B increases confirm improved end organ (brain) status. These findings indicate that serum S-100B is a simple and reliable marker of successful therapeutic treatment on infarct volume reduction and may help identify effective methods of neuroprotection and thrombolysis.

Previous studies in the development of tPA therapy demonstrated improved outcomes in varied animal models of 
stroke, showing the thrombolytic and reperfusion potential of tPA $[11,13]$. In the present study with an angiographic model of embolic stroke, treatment with tPA resulted in numerically decreased infarct volumes (nearly a $50 \%$ reduction) but did not reach statistical significance. Although this endpoint trended in the expected manner, the sample size was too low and the statistical power insufficient to detect a definite difference. Further, S-100B elevation 24 hours after clot embolism was similar to controls and, thus, tPA was not as effective as MB+US in treating stroke. When tPA achieves thrombolysis and reperfusion earlier, it provides significant neuroprotection. However, continued occlusion and ischemia result in adverse effects including blood-brain barrier (BBB) disruption and infarction. Elevations in serum S-100B similar to controls suggest the harmful effects of BBB permeability in rabbits in which tPA did not provide early thrombolysis.

Although measurements of S-100B 24 hours after embolization of the middle cerebral artery were useful when compared with baseline levels, the lack of follow-up beyond 24 hours represents a limitation of the present study. Animal studies [14] as well as clinical data indicate that elevated concentrations of S-100B persist for some days, with peaks observed past 24 hours. Future studies in this rabbit model will examine the development of S-100B over several days and compare this to functional outcomes and histology.

In conclusion, $\mathrm{S}-100 \mathrm{~B}$ can be measured in rabbits and its values correlate with damage from stroke and successful response to treatment. This simple measurement may provide an easy and reliable surrogate marker for successful clot lysis in subsequent thrombolysis trials.

\section{ACKNOWLEDGEMENTS AND FUNDING}

\section{Sources of Funding}

R01 HL082481.

\section{REFERENCES}

[1] Jauch EC, Lindsell C, Broderick J, Fagan SC, Tilley BC, Levine SR and for the NINDS rt-PA Stroke Study Group. Association of Serial Biomarkers With Acute Ischemic Stroke: The National Insti- tute of Neurological Disorders and Stroke Recombinant Tissue Plasminogen Activator Stroke Study. Stroke 2006; 37: 2508-13.

[2] Stroick M, Fatar M, Ragoschke-Schumm A, Fabender K, Bertsch T, Hennerici MG. Protein S-100B- a prognostic marker for cerebral damage. Curr Med Chem 2006; 13: 3053-60.

[3] Büttner T, Weyers S, Postert T, Sprengelmeyer R, Kuhn W. S-100 protein: serum marker of focal brain damage after ischemic territorial MCA infarction. Stroke 1997; 28: 1961-5.

[4] Foerch C, Du Mesnil de Rochemont R, Singer O, et al. S100B as a surrogate marker for successful clot lysis in hyperacute middle cerebral artery occlusion. J Neurol Neurosurg Psychiatry 2003; 74: 322-5.

[5] Foerch C, Singer OC, Neumann-Haefelin T, du Mesnil de Rochemont R, Steinmetz H, Sitzer M. Evaluation of serum S100B as a surrogate marker for long-term outcome and infarct volume in acute middle cerebral artery infarction. Arch Neurol 2005; 62: $1130-4$

[6] Herrmann M, Vos P, Wunderlich MT, de Bruijn CHMM, Lamers KJB. Release of Glial Tissue-Specific Proteins After Acute Stroke : A Comparative Analysis of Serum Concentrations of Protein S100B and Glial Fibrillary Acidic Protein. Stroke 2000; 31: 2670-7.

[7] Missler U, Wiesmann M, Friedrich C, Kaps M. S-100 protein and neuron-specific enolase concentrations in blood as indicators of infarction volume and prognosis in acute ischemic stroke. Stroke 1997; 28: 1956-60.

[8] Serarslan Y, Bal R, Altuğ ME, Kontaş T, Melek İM. Caffeic acid phenethyl ester decreases the level of S-100B protein after middle cerebral artery occlusion in rabbits. Pak J Pharm Sci 2009; 22: 313 6.

[9] Tanaka Y, Koizumi C, Marumo T, Omura T, Yoshida S. Serum $\mathrm{S} 100 \mathrm{~B}$ is a useful surrogate marker for long-term outcomes in photochemically-induced thrombotic stroke rat models. Life Sci 2007; 81: 657-63

[10] Tanaka Y, Marumo T, Omura T, Yoshida S. Serum S100B indicates successful combination treatment with recombinant tissue plasminogen activator and MK-801 in a rat model of embolic stroke. Brain Res 2007; 1154: 194-9.

[11] Zivin JA, Fisher M, DeGirolami U, Hemenway CC, Stashak JA. Tissue plasminogen activator reduces neurological damage after cerebral embolism. Science 1985; 230: 1289-92.

[12] Culp BC, Brown AT, Erdem E, Lowery J, Culp WC. Selective intracranial magnification angiography of the rabbit: basic techniques and anatomy. J Vasc Interv Radiol 2007; 18: 187-92.

[13] Sakurama T, Kitamura R, Kaneko M. Tissue-type plasminogen activator improves neurological functions in a rat model of thromboembolic stroke. Stroke 1994; 25: 451-6.

[14] Tanaka Y, Marumo T, Omura T, Yoshida S. Relationship between cerebrospinal and peripheral S100B levels after focal cerebral ischemia in rats. Neurosci Lett 2008; 436: 40-3.

(C) Woods et al.; Licensee Bentham Open.

This is an open access article licensed under the terms of the Creative Commons Attribution Non-Commercial License (http://creativecommons.org/licenses/by-nc/3.0/) which permits unrestricted, non-commercial use, distribution and reproduction in any medium, provided the work is properly cited. 